\title{
Evaluation of atmospheric instability indices in Greece
}

\author{
A. Marinaki ${ }^{1}$, M. Spiliotopoulos ${ }^{1,2}$, and H. Michalopoulou ${ }^{1}$ \\ ${ }^{1}$ Department of Applied Physics, Laboratory of Meteorology, University of Athens, Greece \\ ${ }^{2}$ Department of Management of Environment and Natural Resources, University of Thessaly, Volos, Greece
}

Received: 10 November 2005 - Revised: 21 December 2005 - Accepted: 16 January 2006 - Published: 16 February 2006

\begin{abstract}
The potential of instability indices in assessing atmospheric instability is examined for the areas of Attica, Thessaly and Central Aegean and Crete, Greece. Generally, many indices have been developed to estimate the troposphere's stability for forecasting purposes. At this study several instability indices, commonly used in Meteorology, are computed based on radiosonde data. Firstly, the indices are computed for several months based on the 00:00 and 12:00 UTC radiosonde data during the period 1981-2003. Statistical methods were used to compare and test the effectiveness of these indices in the described area using meteorological data from seventeen meteorological stations of Greece. Thus, the potential of monitoring the atmospheric instability conditions is examined. The next stage of this study is an effort to test the thresholds of the existing indices in order to improve the results of these indices. It seems that this effort can make a good simulation to the assessment of instability, contributing to local level weather forecasting.
\end{abstract}

\section{Introduction}

Thunderstorms and showers are very important phenomena affecting every aspect of human life. It is already known that in order to estimate the possibility of the development of thunderstorms, atmospheric instability is a major determinant especially in warm period weather. Generally, an unstable atmosphere tends to fire up showers or thunderstorms while a stable atmosphere usually brings sunny skies. The analysis of the atmosphere during the thunderstorms leads the scientific community to develop parameters that would indicate whether or not the conditions are favourable for thunderstorm development. Even if the development of medium scale numerical models enables forecasting of thunderstorms it is still worth to estimate instability with such a traditional way like the instability indices.

Correspondence to: M. Spiliotopoulos

(spilioto@uth.gr)
The estimation of atmospheric instability with the use of instability indices generally requires computation based on several thermodynamic parameters (Showalter, 1953; George, 1960; Boyden, 1963; Jefferson, 1963a, b; Miller, 1967; Litynska et al., 1976; Peppler, 1988; Peppler and Lamb, 1989; Jacovides and Yonetani, 1990; Reuter and Aktary, 1993). Instability indices have been developed and used to aid both research and operational forecasting of severe weather and thunderstorms by quantifying the thermodynamic instability with the aid of radiosonde data. A thorough comparison of instability indices for the Greek peninsula has been carried out in the near past (Dalezios and Papamanolis, 1991; Michalopoulou and Karadana, 1996; Sioutas and Flocas, 2003; Chrysoulakis et al., 2005). All these studies suffer from data deficiency and reliability that comes from the sparse existing radiosonde network. In general, it should be noticed that all the instability indices describe the potential of convection but the referred threshold values are not definite, but may vary with geographical location, season and synoptic situation (Michalopoulou and Jacovides, 1987; Prezerakos, 1989; Dalezios and Papamanolis, 1991; Haklander and Van Delden, 2003). The objective of this study is to investigate which index and where is the most appropriate for instability monitoring as well as to improve the prevailing thresholds according to each area's profile.

\section{Data and methodology}

Upper air data from the three Greek upper air stations: Elliniko (Athens), Mikra (Thessaloniki) and Heraklion (Crete) are utilized at this study. Several months are examined based on the 00:00 and 12:00 UTC radiosonde data during the period 1981-2003. Attention is given especially to spring and summer months where convective thunderstorms are more usual to occur. Radiosonde data such as Temperature $T$ and Dew Point Temperature $T_{d}$ for basic isobaric levels of 850,700 and $500 \mathrm{hPa}$ are recorded and analyzed. Additionally geodynamic height $Z$ for the $(1000-700) \mathrm{hPa}$ 


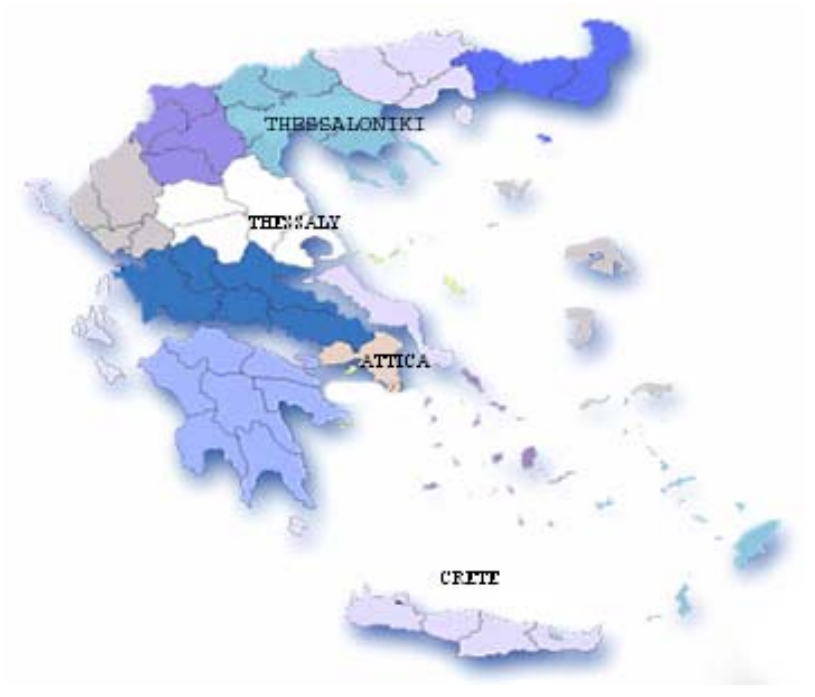

Fig. 1. Map of the study area, showing the related regions of Greece.

thickness, Potential Temperature $\theta$ for each isobaric level and wet bulb Potential Temperature $\theta_{w}$ are computed. Finally, lapse rate $\Gamma$, saturated lapse rate $\Gamma_{s}$ and Relative Humidity $\mathrm{RH}$ are considered for each case.

Each day is recorded as thunderstorm day if a thunderstorm event is observed at least for one station of each area. Rainfall data are observed from 17 Greek meteorological stations located at three regions (Fig. 1):

- Attica (Elliniko, N. Philadelphia, National Observatory of Athens, Dekeleia and Eleysina).

- Thessaly and Central Aegean (Aghialos, Trikala, Larisa, Skiathos and Skyros)

- Crete (Chania, Heraklio, Tympaki, Rethimno, Kasteli, Ierapetra and Siteia).

Usually, instability indices are employed to alert the meteorologist on thunderstorm possibility. Generally, a certain threshold value is defined above (or below) which the possibility of thunderstorms is considered (Haklander and Van Delden, 2003). Another aim of this study has been to derive threshold values that perform best in a dichotomous forecasting scheme that is to divide its range of values into two parts in which a thunderstorm event is either forecast or not forecast. Thus, the thunderstorm probability increases monotonically with either decreasing or increasing index values, according to a benchmark value to distinguish between "thunderstorm" or "no-thunderstorm" forecasts. This benchmark value is called an upper threshold value or a lower threshold value according to if a thundery case is forecasting when the index value lies at or below that benchmark value (a nonthundery case is forecast otherwise). When using the various thunderstorm indices and parameters in such a two-class categorical forecasting scheme, it makes sense to associate them with their optimal threshold values. The threshold value with
Table 1. Consistency table.

\begin{tabular}{lccc}
\hline Forecast/Observed & Yes & No & Total \\
\hline Yes & $\mathrm{a}$ & $\mathrm{b}$ & $\mathrm{a}+\mathrm{b}$ \\
No & $\mathrm{c}$ & $\mathrm{d}$ & $\mathrm{c}+\mathrm{d}$ \\
Total & $\mathrm{a}+\mathrm{c}$ & $\mathrm{b}+\mathrm{d}$ & $\mathrm{a}+\mathrm{b}+\mathrm{c}+\mathrm{d}$ \\
\hline
\end{tabular}

the best performance is chosen to be associated with that particular predictor (Haklander and Van Delden, 2003).

Every meteorological station of the study region gives the observed information of yes or no event. The objective of this study is to investigate which index and where is the most appropriate for instability monitoring as well as to improve the prevailing thresholds according to each area's profile. For this reason the consistency table (Table 1) is constructed.

For the examination of atmospheric instability seven instability indices are examined. The indices used are described as follows:

- Showalter Index (Showalter,1953):

$$
S I=T_{500 \mathrm{hPa}}-T_{850 \mathrm{hPa}-500 \mathrm{hPa}}
$$

- K Index (George, 1960):

$$
K I=\left(T_{850}-T_{500}\right)+T_{d 850}-\left(T_{700}-T_{d 700}\right)
$$

- Boyden Index (Boyden, 1963):

$$
B I=Z-T_{700}-200
$$

where, $Z$ is the difference between the geopotential height between $700 \mathrm{hPa}$ and $1000 \mathrm{hPa}$

- Jefferson Index (Jefferson, 1963a;b):

$$
J I=1.60 \theta_{w 850}-T_{500}-\frac{1}{2}\left(T-T_{d}\right)_{700}-8
$$

- Total Totals Index (Miller, 1967) :

$$
T T=\left(T_{850}-T_{500}\right)+\left(T_{d 850}-T_{d 500}\right)
$$

- Humidity Index (Litynska et al, 1976) :

$$
H I=\left(T-T_{d}\right)_{850}+\left(T-T_{d}\right)_{700}+\left(T-T_{d}\right)_{500}
$$

- Yonetani Index (Jacovides and Yonetani, 1990):

$$
\begin{aligned}
& Y I=0.966 \Gamma_{(900-800) \mathrm{hPa}}+2.41\left(\Gamma_{(850-800) \mathrm{hPa}}-\Gamma_{S 850 \mathrm{hPa}}\right) \\
& +9.66\left(\frac{R H}{100}\right)-15.5, \quad \text { if } R H>57: \\
& Y I=0.966 \Gamma_{i}+2.41\left(\Gamma_{a}-\Gamma_{s}\right)+9.66 \frac{R H}{100}-17, \\
& \text { if } R H<57
\end{aligned}
$$


Table 2. General Results.

\begin{tabular}{|c|c|c|c|c|c|c|c|c|c|c|c|c|c|}
\hline & Month & Jan & Feb & Mar & Apr & May & Jun & Jul & Aug & Sep & Oct & Nov & Dec \\
\hline \multirow[t]{6}{*}{ SI } & ATTICA & & & & & & & & & & & & \\
\hline & threshold & & & & $\leq 6$ & $\leq 6$ & $\leq 6$ & & & & & & \\
\hline & Yule & & & & 0,14 & 0,13 & 0,27 & & & & & & \\
\hline & THESSALY & & & & & & & & & & & & \\
\hline & threshold & & & & $\leq 5$ & $\leq 6$ & $\leq 50$ & $\leq 3$ & $\leq 3$ & $\leq 5$ & $\leq 5$ & & \\
\hline & Yule & & & & 0,19 & 0,12 & 0,15 & 0,19 & 0,18 & 0,22 & 0,26 & & \\
\hline \multirow[t]{8}{*}{$\mathrm{KI}$} & ATTICA & & & & & & & & & & & & \\
\hline & threshold & & & & $\leq 20$ & $\leq 10$ & $\leq 20$ & & & & & & \\
\hline & Yule & & & & 0,14 & 0,19 & 0,26 & & & & & & \\
\hline & THESSALY & & & & & & & & & & & & \\
\hline & thresholds & & & & $\leq 25$ & $\leq 10$ & $\leq 10$ & $\leq 15$ & $\leq 15$ & $\leq 10$ & $\leq 10$ & & \\
\hline & Yule & & & & 0,30 & 0,19 & 0,20 & 0,23 & 0,23 & 0,23 & 0,26 & & \\
\hline & $\begin{array}{l}\text { CRETE } \\
\text { thresholds }\end{array}$ & $\leq 26$ & $\leq 31$ & $\leq 34$ & $\leq 25$ & $\leq 29$ & $\leq 35$ & $\leq 33$ & $\leq 35$ & $\leq 35$ & $\leq 35$ & $\leq 30$ & $\leq 25$ \\
\hline & Yule & 0,34 & $\overline{0,42}$ & 0,46 & $\overline{0}, 30$ & $\overline{0}, 40$ & 0,34 & 0,42 & $\overline{0,46}$ & $\overline{0,38}$ & 0,34 & 0,35 & 0,34 \\
\hline \multirow[t]{6}{*}{ BI } & ATTICA & & & & & & & & & & & & \\
\hline & thresholds & & & & $\leq 95$ & $\leq 95$ & $\leq 94$ & & & & & & \\
\hline & Yule & & & & 0,09 & 0,09 & 0,14 & & & & & & \\
\hline & THESSALY & & & & & & & & & & & & \\
\hline & Threshold & $\leq 95$ & $\leq 90$ & $\leq 95$ & $\leq 95$ & $\leq 95$ & $\leq 95$ & $\leq 95$ & $\leq 95$ & $\leq 95$ & $\leq 95$ & $\leq 95$ & $\leq 90$ \\
\hline & Yule & 0,10 & 0,04 & 0,04 & 0,13 & 0,08 & 0,14 & 0,13 & 0,20 & 0,12 & 0,14 & 0,08 & 0,06 \\
\hline \multirow[t]{8}{*}{ JI } & ATTICA & & & & & & & & & & & & \\
\hline & threshold & & & & $\leq 20$ & $\leq 30$ & $\leq 25$ & & & & & & \\
\hline & Yule & & & & 0,17 & $\overline{0,02}$ & 0,25 & & & & & & \\
\hline & THESSALY & & & & & & & & & & & & \\
\hline & thresholds & & & & $\leq 25$ & $\leq 24$ & $\leq 28$ & $\leq 27$ & $\leq 25$ & $\leq 26$ & $\leq 27$ & & \\
\hline & Yule & & & & 0,26 & 0,22 & 0,44 & 0,34 & 0,44 & 0,39 & 0,33 & & \\
\hline & $\begin{array}{l}\text { CRETE } \\
\text { thresholds }\end{array}$ & $\leq 26$ & $\leq 29$ & $\leq 27$ & $\leq 23$ & $\leq 27$ & $\leq 30$ & $\leq 30$ & $\leq 27$ & $\leq 29$ & $\leq 29$ & $\leq 25$ & $\leq 25$ \\
\hline & Yule & 0,36 & 0,33 & 0,32 & 0,28 & 0,42 & 0,44 & 0,40 & 0,46 & 0,42 & 0,44 & 0,46 & 0,32 \\
\hline \multirow[t]{3}{*}{ TT } & THESSALY & & & & & & & & & & & & \\
\hline & thresholds & & & & $\leq 50$ & $\leq 45$ & $\leq 45$ & $\leq 45$ & $\leq 40$ & $\leq 45$ & $\leq 10$ & & \\
\hline & Yule & & & & 0,24 & 0,19 & 0,26 & 0,27 & 0,29 & 0,36 & 0,22 & & \\
\hline \multirow[t]{5}{*}{ HI } & ATTICA & & & & & & & & & & & & \\
\hline & threshold & & & & $\leq 30$ & $\leq 40$ & $\leq 25$ & & & & & & \\
\hline & Yule & & & & 0,23 & 0,23 & 0,20 & & & & & & \\
\hline & $\begin{array}{l}\text { THESSALY } \\
\text { thresholds }\end{array}$ & $\leq 40$ & $\leq 40$ & $\leq 40$ & $\leq 35$ & $\leq 45$ & $\leq 45$ & $\leq 45$ & $\leq 45$ & $\leq 45$ & $\leq 35$ & $\leq 35$ & $\leq 40$ \\
\hline & Yule & 0,19 & 0,13 & 0,19 & $\overline{0}, 23$ & $\overline{0}, 17$ & 0,29 & 0,37 & $\overline{0,31}$ & $\overline{0}, 18$ & $\overline{0}, 23$ & $\overline{0}, 17$ & 0,19 \\
\hline \multirow[t]{3}{*}{ YI } & ATTICA & & & & & & & & & & & & \\
\hline & thresholds & & & & $\leq-1$ & $\leq-2$ & $\leq 0$ & & & & & & \\
\hline & Yule & & & & 0,21 & 0,19 & 0,13 & & & & & & \\
\hline
\end{tabular}

Finally, according to Table 1 Yule Index is applied given by Eq. (8):

$Y=\frac{(a d-b c)}{[(a+b)(b+d)(a+c)(c+d)]^{1 / 2}}$

The first attempt in this study was to compute the seven described instability indices for the Attica region, taking into account only Elliniko station, but finally it was decided to work not only with Attica region incorporating Thessaly and Crete. Unfortunately, in order to work with these regions, Mikra and Heraklion upper-air stations were necessary for data acquirement, but, for the study period there were too many data loses for 12:00 UTC. Thus, it was decided to proceed with the 00:00 UTC. It is well known that 12:00 UTC represents convective phenomena better than 00:00 UTC, but, the authors believe that 00:00 UTC may have a better forecasting value because it comes many hours before the formation of convection. 
Table 3. Jefferson Index: Best thresholds.

\begin{tabular}{|c|c|c|c|c|c|c|}
\hline & month & Apr-May & & Jun & & \\
\hline ATTICA & threshold & $\geq 20$ & & $\geq 25$ & & \\
\hline THESSALY & $\begin{array}{l}\text { month } \\
\text { threshold }\end{array}$ & $\begin{array}{l}\text { Apr-May } \\
\geq 25\end{array}$ & & $\begin{array}{l}\text { Jun-Jul-Aug } \\
\geq 28\end{array}$ & $\begin{array}{l}\text { Sep-Oct } \\
\geq 27\end{array}$ & \\
\hline CRETE & $\begin{array}{l}\text { month } \\
\text { threshold }\end{array}$ & $\begin{array}{l}\text { Apr } \\
\geq 23\end{array}$ & $\begin{array}{l}\text { Feb-Mar-May } \\
\geq 27\end{array}$ & $\begin{array}{l}\text { Jun-Jul-Aug } \\
\geq 30\end{array}$ & $\begin{array}{l}\text { Sep-Oct } \\
\geq 29\end{array}$ & $\begin{array}{l}\text { Nov-Dec-Jan } \\
\geq 26\end{array}$ \\
\hline
\end{tabular}

\section{Results}

Yule index is applied for every index and every region for this study. The result of such an application gives Table 2. Table 2 shows the values of Yule index for every one of the seven applied instability indices and for each of the three regions under consideration. Empty values indicate that there is no available radiosonde data.

According to Yule criterion Jefferson Index seems to be the most appropriate index for this study. Furthermore in order to find the appropriate periods with the best thresholds a new examination of the Yule Index gives Table 3 which describes the combinations of best thresholds as well as the corresponding periods for Jefferson instability index.

The general idea behind the analysis of the related periods is to find one threshold which fits better to the Yule criterion for consecutive months. It is found from the analysis that there is not too much alteration to the Yule value when the thresholds are shuffled for 1 or 2 points. This concept leads to a less complicated solution for the estimation of instability in space and time. According to this acceptance, Jefferson Index with threshold 25 has the best performance for Thessaly region for the summer months. According to Tables 2 and 3, for Crete Island Yule criterion gives that the best values are computed with threshold 30 for the summer months.

For the greater Attica region Humidity Index is found to be enough satisfactory, with the best thresholds at April-May $(\leq 40)$ and June $(\leq 25)$. For Crete Island K Index is found to be also enough satisfactory with the best thresholds at April $(\geq 25)$, December - January $(\geq 26)$ and February-MarchJune-July-August-September-October ( $\geq 35)$.

\section{Conclusions}

In this study, seven instability indices were computed. Each one of the seven indices was tested as independent, but, the truth is that these seven instability types are certainly not independent. It seems that because of the manifold of the Greek Peninsula, air masses have many and different geographical sources. This fact together with the great elevation differences lead to a very complex response of the instability indices. Jefferson index seems to be the best for this study but, generally, an ideal index should, presumably, delineate space-time domains inside which the forecast events occur and outside of which the forecast events do not occur. Gen- erally, it can be said that an index is a necessary ingredient but is not by itself sufficient. The fact is that an index can focus attention on places and times where the forecast events are likely to occur. In near future many techniques will have to improve the effectiveness of these indices as well as their spatial applicability. According to this it would be a very good idea to correlate SKIRON's modelling system output with such instability indices in a future work.

Acknowledgements. The authors thank Greek National Meteorological Service for the provided atmospheric soundings data for the three upper-air stations and the meteorological data from the seventeen surface stations used at this study.

Edited by: V. Kotroni and K. Lagouvardos

Reviewed by: anonymous referee

\section{References}

Boyden, C. J.: A simple instability index for use as a synoptic parameter, Meteorological Magazine, 92, 198-210, 1963.

Chrysoulakis, N., Spiliotopoulos, M., Domenikiotis, C., and Dalezios, N. R.: Investigation of the atmospheric instability using remotely sensed data, in: Proceedings of the International Symposium on GIS and Remote Sensing: Environmental Applications, edited by: Dalezios, N. R. and Dobesch, H., Volos, Greece, 7-9 November 2003, 155-166, 2005.

Dalezios, N. R. and Papamanolis, N. K.: Objective assessment of instability indices for operational hail forecasting in Greece, Meteorol. Atmos. Phys., 45, 87-100, 1991.

George, J. J.: Weather forecasting for Aeronautics, Academic Press, New York, 409-415, 1960.

Haklander, A. J. and Van Delden, A.: Thunderstorm predictors and their forecast skill for the Netherlands, Atmos. Res., 67-68, 273299, 2003.

Jacovides, C. P. and Yonetani, T.: An evaluation of stability indices for thunderstorm prediction in Greater Cyprus, Weather Forecast, 5, 559-569, 1990.

Jefferson, G. J.: A modified instability index, Meteorological Magazine, 92, 92-96, 1963a.

Jefferson, G. J.: A further development of the instability index, Meteorological Magazine, 92, 313-316, 1963b.

Litynska, Z., Parfiniewicz, J., and Pinkowski, H.: The prediction of air mass thunderstorms and hails, W.M.O., No. 450, 128-130, 1976.

Michalopoulou, H. and Jacovides, C.: Instability Indices for the Cyprus Area, Meteorol. Atmos. Phys., 37, 153-158, 1987. 
Michalopoulou, H. and Karadana, E.: A review of instability indices for the greater area of Athens, 3rd Hellenic Conference on Meteorology and Atmospheric Physics, 193-198, 1996.

Miller, R. C.: Note on analysis and severe storm forecasting procedures of the Military Weather Warning Center, AWS Tech. Rep. 200, USAF, Scott AFB, IL, 94 pp., 1967.

Peppler, R. A.: A review of static stability indices and related thermodynamic parameters, Illinois State Water Survey Misc. Publ. 104, (Illinois State Water Survey, 2204 Griffith Drive, Champaign, IL 61820), 87 pp.,1988.

Peppler, R. A. and Lamb, P. J.: Tropospheric static stability and central North American growing season rainfall, Mon. Wea. Rev., 117, 1156-1180, 1989.
Prezerakos, N. G.: An investigation into the conditions in which airmass thunderstorms occur at Athens, Meteorological Magazine, 118 (1399), 31-36, 1989.

Reuter, G. W. and Aktary, N.: A slantwise Showalter index based on moist symmetric instability: Results for Central Alberta, Atmosphere-Ocean, 31, 379-394, 1993.

Showalter, A. K.: A stability index for thunderstorm forecasting, Bull. Amer. Meteorol. Soc., 34, 250-252, 1953.

Sioutas, M. V. and Flocas, H. A.: Hailstorms in Northern Greece: synoptic patterns and thermodynamic environment, Theor. Appl. Climatol., 75, 189-202, 2003. 